\title{
PERBANDINGAN HASIL PEMERIKSAAN TAJAM PENGLIHATAN JAUH ANTARA APLIKASI PERANGKAT LUNAK PEEK ACUITY DENGAN SNELLEN CHART
}

\author{
Dwi Sekar Laras ${ }^{1)}$, Dicky Aditya Sukma ${ }^{2)}$ \\ ${ }^{1}$ Dosen Program Studi Diploma Tiga Opthometri STIKes Dharma Husada Bandung \\ ${ }^{2}$ Mahasiswa Program Studi Diploma Tiga Opthometri STIKes Dharma Husada Bandung \\ Dwie_sl@yahoo.co.id
}

\begin{abstract}
Abstrak
Pemeriksaan tajam penglihatan merupakan salah satu pemeriksaan terpenting untuk dapat menilai fungsi visual seseorang. Snellen chart adalah media yang paling sering digunakan untuk pengukuran tajam penglihatan pada praktik kedokteran sehari-hari. Namun, kekurangan kartu Snellen adalah perbedaan ukuran huruf dari baris ke baris berikutnya dan jumlah huruf yang tidak sama di setiap baris. Berkembangnya teknologi telepon selular telah meluncurkan aplikasi pada seluler yang dapat mengukur tajam penglihatan, yaitu Peek Acuity Aplikasi Portable Eye Examination Kit (PEEK) Acuity yang diluncurkan pada sistem android. Peneliti ingin membandingkan hasil tajam penglihatan antara aplikasi perangkat lunak PEEK Acuity dengan Snellen Chart. Dengan metode study literature yaitu cara yang dipakai untuk menghimpun data-data atau sumber-sumber yang berhubungan dengan topik yang diangkat dalam penelitian. Berdasarkan hasil kajian literatur didapatkan bahwa aplikasi perangkat lunak PEEK Acuity lebih cepat dalam waktu penggunaan dibanding Snellen Chart, aplikasi perangkat lunak PEEK Acuity tidak membutuhkan luas ruang yang terlalu besar jika dibanding Snellen Chart, aplikasi perangkat lunak PEEK Acuity dapat di unduh gratis namun membutuhkan biaya untuk pengadaan telepon pintar dengan kualitas layar tinggi, dan penggunaan aplikasi perangkat lunak PEEK Acuity dapat disarankan untuk melakukan screening karena sensifitasnya yang tinggi. Namun, tidak disarankan untuk di jadikan rujukan dan/atau digunakan untuk alat utama pemeriksaan visus secara komprehensif di klinik.
\end{abstract}

Kata Kunci : PEEK AQUITY, Snellent Chart, Aplikasi telepon pintar,Pemeriksaan Visus

\section{PENDAHULUAN}

Hasil systematic review dan metaanalysis dari data berbasis populasi yang relevan dengan gangguan penglihatan dan kebutaan global yang dipublikasikan tahun 1980-2015 mendapatkan hasil pada tahun 2015 diperkirakan dari 7,33 triliun penduduk dunia terdapat 253 juta orang $(3,38 \%)$ yang menderita gangguan penglihatan, yang terdiri dari 36 juta orang mengalami kebutaan, 217 juta mengalami gangguan penglihatan sedang hingga berat. Di samping itu terdapat 188 juta orang mengalami gangguan penglihatan ringan. (Pusat Data dan Informasi Kementerian Kesehatan RI, 2018)

Gangguan penglihatan dan kebutaan di Indonesia terus mengalami peningkatan dengan prevalensi $1.5 \%$ dan tertinggi dibandingkan dengan angka kebutaan di negara - negara regional Asia Tenggara. Penyebab gangguan penglihatan dan kebutaan tersebut adalah glaukoma (13.4\%), kelainan refraksi (9.5\%), gangguan retina $(8.5 \%)$, 
JURNAL SEHAT MASADA VOLUME XVI kelainan kornea $(8.4 \%)$, dan penyakit mata lainnya. (Witjaksono \& Riani, 2018)

Tindakan koreksi yang dilakukan adalah mencakupi kacamata, lensa kontak, serta bedah refraksif seperti LASIK (Laser-Assisted In Situ Keratomileusis) atau bedah dengan sinar laser, clear lens extraction, phakic intraokular lensa, radial keratotomy, keratektomi fotorefraksif, dan keratoplasi lamellar automated (ALK). (Ilyas \& Yulianti, 2017)

Pemeriksaan refraksi didefinisikan sebagai pengukuran terhadap gangguan refraksi dan merupakan penerapan klinis dari prinsip optik oleh seorang pemeriksa dengan menggunakan instrumen dari yang sederhana hingga menggunakan alat yang canggih. Pemeriksaan refraksi dibagi menjadi dua kategori yaitu pemeriksaan objektif dan subjektif. (Direktoral Jenderal Pelayanan Kesehatan, 2018)

Pemeriksaan subyektif terdiri beberapa tahapan yaitu: Penentuan visus dasar terbaik dan ketajaman penglihatan, Penentuan Best Visus Sphere (BVS), metode penentuan astigmatis, teknik keseimbangan binokuler, titik akhir binokuler, mencatat hasil akhir dengan Best Corrected Visual Acuity (BCVA) salah satu mata dan kedua mata. (Witjaksono \& Riani, 2018)

Untuk mengukur tajam penglihatan, diperlukan suatu obyek yang berupa Optotype. Ada beberapa macam Optotype yaitu: Snellen Chart, Bailey-Lovie Chart dan University Waterloo Chart. Yang paling banyak digunakan adalah Snellen Chart. (Inggito, 2016)
NOMOR 1 Januari 2022 ISSN : 1979-2344

Kartu Snellen adalah media yang paling sering digunakan untuk pengukuran tajam penglihatan pada praktik kedokteran seharihari (Bastawrous A, 2015). Penggunaan kartu baca Snellen masih banyak digunakan pada praktik klinis. Hal ini dikarenakan kartu baca Snellen telah dikenali oleh kalangan luas serta memiliki sistem penilaian yang mudah dipahami, mempunyai ukuran yang lebih kecil serta hanya memerlukan waktu yang singkat dalam penggunaannya dibandingkan kartu baca ETDRS. (Putranto, 2017)

Namun, kekurangan kartu Snellen adalah perbedaan ukuran huruf dari baris ke baris berikutnya dan jumlah huruf yang tidak sama di setiap baris. Jenis huruf yang berbedabeda dan terdiri dari beberapa baris juga memberikan efek sekunder seperti fenomena crowding yang diketahui dapat mempengaruhi kemampuan pasien untuk membedakan huruf (optotype) dengan benar. (Bastawrous A, 2015) (Brady C, 2015) Namun karena harga kartu LogMAR relatif lebih mahal, kartu Snellen tetap menjadi metode utama untuk memeriksa tajam penglihatan dalam praktik klinis. (Chen F, 2014) (PK, 2009)

Berkembangnya teknologi telepon selular telah meluncurkan aplikasi pada seluler yang dapat mengukur tajam penglihatan, yaitu PEEK Acuity Aplikasi Portable Eye Examination Kit (PEEK) Acuity yang diluncurkan pada sistem android merupakan aplikasi yang didesain mengikuti standar kartu ETDRS untuk pengukuran tajam penglihatan yang ditampilkan dalam notasi Snellen metric 
JURNAL SEHAT MASADA VOLUME XVI

(6/6) dan imperial (20/20) atau satuan

LogMAR. (Cicendo Eye Hospital, 2019)

\section{METODOLOGI}

Metode pengumpulan data dengan metode study literature yaitu yang dipakai untuk menghimpun data-data atau sumbersumber yang berhubungan dengan topik yang diangkat dalam suatu penelitian.

Metode analisis yang digunakan adalah dengan menggunakan Literature review matrix yaitu dengan menggabungkan berbagai jurnal baik jurnal nasional maupun
NOMOR 1 Januari 2022 ISSN : 1979-2344

jurnal internasional yang bersifat relevan, mutakhir, dan memadai, lalu setelah itu mencari kesamaan dan perbedaan dari berbagai data yang di gunakan adalah data sekunder dari jurnal, laporan, textbook,internet, pustaka dan lainnya.

\section{HASIL}

\begin{tabular}{|c|c|c|c|}
\hline No. & $\begin{array}{l}\text { Nama, Judul, } \\
\text { Tahun Publikasi }\end{array}$ & Metode & Hasil \\
\hline 1 & $\begin{array}{l}\text { Nama Peneliti : } \\
\text { Saphira Evani, } \\
\text { Andika A. Witono, } \\
\text { Fabian J. Junaidi } \\
\text { Judul : } \\
\text { Perbandingan Hasil } \\
\text { Pemeriksaan Tajam } \\
\text { Penglihatan } \\
\text { Menggunakan } \\
\text { Snellen Chart dan } \\
\text { Aplikasi telepon } \\
\text { pintar PEEK Acuity } \\
\text { pada Anak Usia 5-6 } \\
\text { Tahun } \\
\text { Tahun Publikasi : } \\
\text { 23 Juli } 2019\end{array}$ & $\begin{array}{l}\text { Desain Penelitian : } \\
\text { Menggunakan metode } \\
\text { observasional analtik dengan } \\
\text { rancangan cross-sectional. } \\
\text { Populasi : } \\
\text { Seluruh siswa/i kelas K2, usia } 5 \\
\text { - } 6 \text { tahun yang hadir pada hari } \\
\text { pemeriksaan pada tanggal } 5 \text { - } 6 \\
\text { Desember } 2018 \text {. } \\
\text { Jumlah Sampel : } \\
\text { Total } 82 \text { orang (33 orang laki- } \\
\text { laki, } 49 \text { orang perempuan). }\end{array}$ & 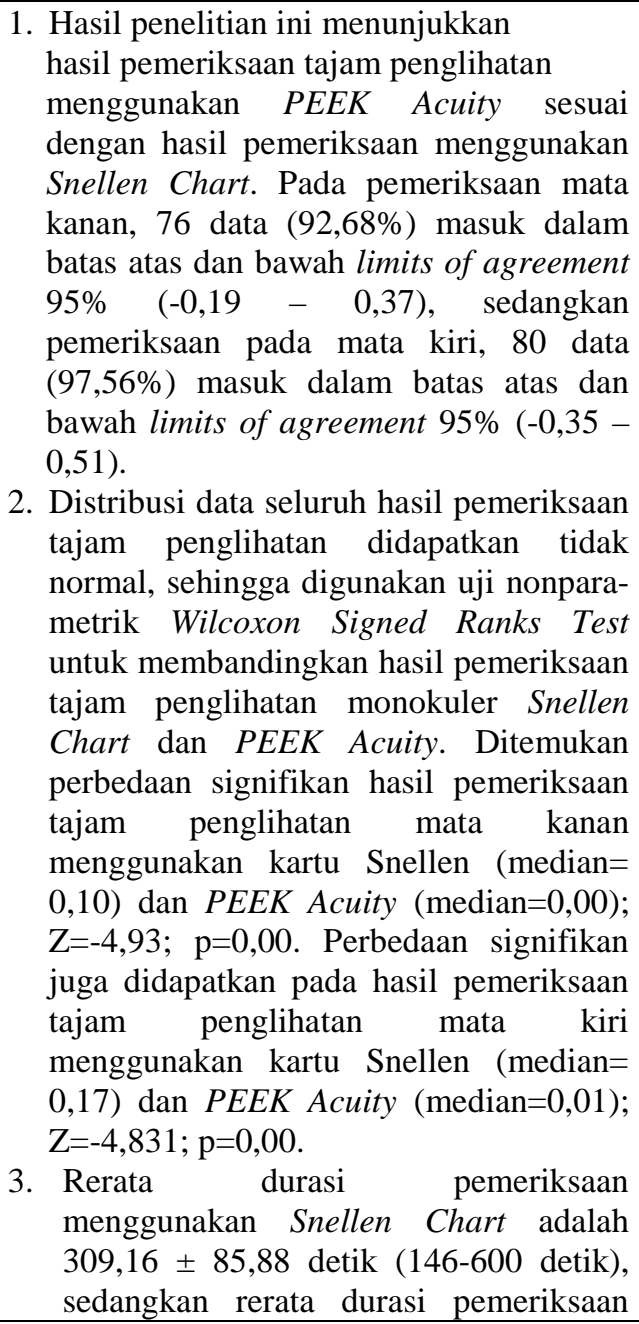 \\
\hline
\end{tabular}




\begin{tabular}{|c|c|c|c|}
\hline & & & $\begin{array}{l}\text { menggunakan PEEK Acuity lebih } \\
\text { pendek, yakni } 136,59 \pm 81,14 \text { detik (42- } \\
420 \text { detik). } \\
\text { 4. Ada perbedaan signifikan durasi } \\
\text { pemeriksaan menggunakan Snellen } \\
\text { Chart dan PEEK Acuity }(\mathrm{z}=-7,419 ; \mathrm{p}= \\
0,00) \text {. } \\
\text { 5. Durasi pemeriksaan menggunakan } \\
\text { PEEK Acuity secara signifikan lebih } \\
\text { singkat dibandingkan Snellen Chart } \\
\text { pada anak usia pra-sekolah (5-6 tahun). }\end{array}$ \\
\hline 2 & $\begin{array}{l}\text { Nama Peneliti : } \\
\text { Andrew Bastawrous, } \\
\text { MRCOpth; Hillary K. } \\
\text { Rono, MBBS; Iain A. } \\
\text { T. Livingstone, } \\
\text { FRCOpth; Helen A. } \\
\text { Weiss, PhD; Stewart } \\
\text { Jordan, BSc; Hannah } \\
\text { Kuper, ScD; Matthew } \\
\text { J. Burton, PhD } \\
\text { Judul : } \\
\text { Development and } \\
\text { Validation of a } \\
\text { Smartphone-Based } \\
\text { Visual Acuity } \\
\text { Test(PEEK Acuity) } \\
\text { for Clinical Practice } \\
\text { and Community- } \\
\text { Based Fieldwork } \\
\text { Tahun Publikasi : } \\
\text { 28 Mei 2015 }\end{array}$ & $\begin{array}{l}\text { Desain Penelitian: } \\
\text { Penelitian ini dilakukan dalam } \\
\text { tindak lanjut selama } 6 \text { tahun } \\
\text { Nakuru Eye Disease Cohort di } \\
\text { Kenya tengah. } \\
\text { Populasi dan Jumlah Sampel : } \\
\text { Melibatkan } 300 \text { orang dewasa } \\
\text { berusia } 55 \text { tahun dan lebih tua } \\
\text { yang direkrut secara berurutan. } \\
\text { Studi ini berlangsung antara } \\
\text { Desember } 2013 \text { dan Maret } \\
\text { 2014. }\end{array}$ & $\begin{array}{l}\text { 1. Batas CI (selang kepercayaan) } 95 \% \text { untuk } \\
\text { variabilitas uji-retest data ketajaman } \\
\text { telepon pintar adalah } \pm 0,033 \\
\text { logMAR. Perbedaan rata-rata antara tes } \\
\text { berbasis telepon pintar dan grafik ETDRS } \\
\text { dan tes berbasis telepon pintar dan data } \\
\text { Snellen Acuity adalah 0,07 (95\% CI, } \\
\text { 0,05-0,09) dan 0,08 (95\% CI, 0,06-0,10) } \\
\text { logMAR, menunjukkan bahwa ketajaman } \\
\text { tes berbasis telepon pintar cocok } \\
\text { (sebanding) dengan grafik ETDRS dan } \\
\text { Snellen. } \\
\text { 2. Kecocokan PEEK Acuity dan bagan } \\
\text { ETDRS lebih besar daripada bagan } \\
\text { Snellen dengan bagan ETDRS (95\% CI, } \\
\text { 0,05-0,10; P = .08) } \\
\text { 3. PEEK Acuity; yang membutuhkan } \\
\text { minimal pelatihan tidak lebih lama dari } \\
\text { tes Snellen 77 detik vs } 82 \text { detik; } 95 \% \text { CI, } \\
\text { 71-84 detik vs 73-91 detik, masing- } \\
\text { masing; P =.13). } \\
\text { 4. Tidak adanya efek samping dari tes } \\
\text { ketajaman penglihatan yang dilaporkan } \\
\text { 5. PEEK Acuity yang digunakan di rumah } \\
\text { oleh petugas kesehatan memiliki } 85 \% \\
\text { sensitifitas dan 98\% spesifik dalam } \\
\text { mendeteksi mata dengan gangguan } \\
\text { penglihatan yang parah (setara dengan } 5 \\
\text { / 60 pada Snellen Chart) }\end{array}$ \\
\hline 3 & $\begin{array}{l}\text { Nama Peneliti : } \\
\text { Christoper J. Brady, } \\
\text { MD; Allen O. Eghart, } \\
\text { MD; AlainB. } \\
\text { Labrique, PhD, MHS, } \\
\text { MS } \\
\text { Judul : } \\
\text { Smartphone-Based } \\
\text { Visual Acuity } \\
\text { Measurement for } \\
\text { Screening and } \\
\text { Clinical Assessment } \\
\text { Tahun Publikasi : } \\
\text { 22 Desember 2015 }\end{array}$ & $\begin{array}{l}\text { Desain Penelitian: } \\
\text { Penelitian ini dilakukan dalam } \\
\text { tindak lanjut selama } 6 \text { tahun } \\
\text { Nakuru Eye Disease Cohort di } \\
\text { Kenya tengah. } \\
\text { Populasi dan Jumlah Sampel : } \\
\text { Melibatkan } 300 \text { orang dewasa } \\
\text { berusia } 55 \text { tahun dan lebih tua } \\
\text { yang direkrut secara berurutan. } \\
\text { Studi ini berlangsung antara } \\
\text { Desember } 2013 \text { dan Maret } \\
2014 \text {. }\end{array}$ & $\begin{array}{l}\text { 1. Seorang dokter atau peneliti yang tertarik } \\
\text { menggunakan aplikasi ini harus } \\
\text { mempertimbangkan beberapa } \\
\text { pertimbangan praktis, seperti : } \\
\text { a. Mengharuskan pengguna untuk } \\
\text { menghitung jarak yang tepat antara } \\
\text { pasien dan pemeriksa } \\
\text { b. Perangkat ponsel pintar yang } \\
\text { mungkin mahal, terutama untuk } \\
\text { model dengan layar yang berkualitas } \\
\text { tinggi } \\
\text { 2. Bahwa penggunaan aplikasi PEEK } \\
\text { Acuity tidak lebih lama dari pengujian } \\
\text { Snellen dan menyimpulkan bahwa } \\
\text { aplikasi tersebut dapat diulang dan } \\
\text { konsisten }\end{array}$ \\
\hline 4 & $\begin{array}{l}\text { Nama Peneliti : } \\
\text { Bryce de Venecia, } \\
\text { Yasmin Bradfiled, }\end{array}$ & $\begin{array}{l}\text { Desain Penelitian : } \\
\text { Metode } \\
\text { menggunakan metode Kohort }\end{array}$ & $\begin{array}{l}\text { 1. Kami memperoleh sensitivitas } 48 \% \text {, } \\
\text { spesifisitas } 83 \%, 43 \% \text { nilai prediktif } \\
\text { positif, dan } 86 \% \text { nilai prediktif negative }\end{array}$ \\
\hline
\end{tabular}




\begin{tabular}{|c|c|c|}
\hline $\begin{array}{l}\text { Ralph Møller Trane, } \\
\text { Alicia Bareiro, } \\
\text { Miguel Scalamogna } \\
\text { Judul : } \\
\text { Validation of PEEK } \\
\text { Acuity application in } \\
\text { pediatric screening } \\
\text { programs in Paraguay } \\
\text { Tahun Publikasi : } \\
18 \text { Agustus } 2018\end{array}$ & $\begin{array}{l}\text { dan berlangsung dari } 3 \text { Juli } 2017 \\
\text { hingga } 31 \text { Oktober 2017, dalam } \\
\text { upaya penyaringan bersama } \\
\text { Combat Blindness International } \\
\text { (Madison, Wisconsin) dan } \\
\text { Fundación Visión (Asuncion, } \\
\text { Paraguay). } \\
\text { Populasi dan Jumlah Sampel : } \\
\text { Penelitian ini diikuti oleh } 393 \\
\text { subjek yang terdaftar dengan } \\
\text { rentang usia anak-anak berkisar } \\
\text { antara 6-16 tahun. }\end{array}$ & $\begin{array}{l}\text { untuk kemampuan PEEK Acuity sebagai } \\
\text { bahan rujukan, dibandingkan dengan } \\
\text { evaluasi oleh dokter spesialis mata anak, } \\
\text { PEEK Acuity gagal mencapai sensitivitas } \\
\text { yang diinginkan } \\
\text { pengimplementasian. } \\
\text { 2. PEEK Acuity cenderung terus untuk } \\
\text { melebih-lebihkan ketajaman visual } \\
\text { pasien, memberikan ketajaman visual } \\
\text { yang lebih tinggi yang tidak akan } \\
\text { menunjukkan rujukan untuk pemeriksaan } \\
\text { mata yang komprehensif } \\
\text { 3. PEEK Acuity merupakan alat yang } \\
\text { efisien yang berpotensi untuk diterapkan } \\
\text { dalam screening di sekolah dengan } \\
\text { berbagai strategi yang ditujukan untuk } \\
\text { usia anak karena biayanya yang rendah } \\
\text { dan mempunyai spesifisitas tinggi. } \\
\text { 4. Penggunaan aplikasi perangkat lunak } \\
\text { PEEK Acuity yaitu dengan menggunakan } \\
\text { telepon pintar Samsung Galaxy A3 } \\
\text { dengan harga } 140 \text { USD, sedangkan biaya } \\
\text { untuk pembelian Tumbling E adalah } 10 \\
\text { USD dan untuk Spot Vision Screener } \\
\text { dengan harga } 6490 \text { USD. }\end{array}$ \\
\hline
\end{tabular}

\section{1) Efektivitas}

Berdasarkan hasil penelitian pada jurnal 1, waktu penggunaan Snellen Chart sebagai alat pemeriksaan visus penglihatan jauh membutuhkan waktu $309,16 \pm 85,88$ detik (146-600 detik), sedangkan penggunaan PEEK Acuity sebagai alat pemeriksaan visus penglihatan jauh membutuhkan waktu yang lebih pendek, yakni 136,59 $\pm 81,14$ detik (42420 detik). Pemeriksaan menggunakan aplikasi tersebut membutuhkan waktu lebih singkat dan dapat digunakan pada pasien yang tidak familiar dengan huruf alfabet. Terbukti pada penelitian pada jurnal 1 ini, rerata durasi pemeriksaan menggunakan PEEK Acuity lebih singkat dibandingkan dengan Snellen Chart $(136,59$ vs 309,16 detik). Begitu pula berdasarkan hasil penelitian pada jurnal 2, waktu pemeriksaan rata-rata untuk kedua mata pada 126 orang ada 82 detik (95\% CI, 73-91 detik) dengan Snellen Chart dan 77 detik (95\% CI, 71-84 detik) dengan PEEK Acuity, tidak menunjukkan perbedaan $(\mathrm{P}=.13)$.

Namun, pada berdasarkan hasil penelitian pada jurnal 4 durasi rata-rata menjalankan setiap teknik pemeriksaan menggunakan Snellen (Tumbling E) 21,63 detik sedangkan PEEK Acuity 56,24 detik. Perbedaan dalam jurnal 4 ini, peneliti juga membandingkan dengan Spot Vision Screener dengan durasi rata-rata pemeriksaan 5,10 detik. Dengan hal tersebut, yang dipaparkan pada hasil penelitian yang di lakukan pada jurnal 4 berbanding terbalik dengan hasil penelitian yang di lakukan pada jurnal 1 dan 2.

Hasil penelitian tersebut disebabkan oleh aplikasi PEEK Acuity hanya menggunakan huruf "E" dalam 4 arah dan subjek/pasien di minta menunjuk ke arah kaki Jurnal Penelitian Kesehatan STIKes Dharma Husada Bandung 
JURNAL SEHAT MASADA VOLUME XVI dari E, sehingga membuat pemeriksaan PEEK Acuity lebih cepat di banding Snellen Chart dengan alfabet. Berbanding terbalik jika dibandingkan dengan Tumbling $E$ dengan standar Snellen Chart, pada Tumbling E dengan Snellen Chart pasien/subjek dapat langsung menyebutkan arah kaki dari E tanpa adanya perpindahan dari setiap baris visus. Berbeda dengan penggunaan PEEK Acuity yang juga membutuhkan tenaga pemeriksa untuk memindahkan layar ke baris visus berikutnya.

\section{2) Biaya Operasional}

Biaya yang di angkat oleh peneliti yaitu biaya di keluarkan oleh pengguna dalam melakukan pemeriksaan visus menggunakan PEEK Acuity dan Snellen Chart.

Berdasarkan hasil pada jurnal 2, dalam penggunaan aplikasi perangkat lunak PEEK Acuity menggunakan telepon seluler Galaxy SIII GT-I9300 dan menyatakan bahwa biaya untuk pembelian telepon pintar secara keseluruhan lebih mahal daripada Snellen Chart tetapi lebih murah dibanding $\log M A R$ atau Snellen Chart Retroilluminated. Dan itu juga sebanding dengan penelitian yang ada pada jurnal 4, pada penelitian tersebut dalam penggunaan aplikasi perangkat lunak PEEK Acuity yaitu dengan menggunakan telepon pintar Samsung Galaxy A3 dengan harga 140 USD, sedangkan biaya untuk pembelian Tumbling E adalah 10 USD dan untuk Spot Vision Screener dengan harga 6490 USD. Sama halnya pada jurnal 1 , dalam penggunaan aplikasi perangkat lunak PEEK Acuity
NOMOR 1 Januari 2022 ISSN : 1979-2344 menggunakan telepon pintar Samsung Galaxy S2.

Berdasarkan dari pemaparan hasil dari jurnal-jurnal di atas membuktikan bahwa meski pun aplikasi perangkat lunak PEEK Acuity ini dapat di unduh secara gratis di telepon pintar berbasis android, tetapi aplikasi ini membutuhkan telepon pintar dalam pengoperasiannya. Namun, di zaman yang sudah canggih seperti sekarang dimana sebagian besar masyarakat sekitar 81,87 juta orang (statiska.com, 2020) di Indonesia telah memiliki telepon pintar hal ini tidak menjadi hambatan untuk melakukan pemeriksaan tajam penglihatan.

\section{3) Efisiensi}

Pada jurnal 1, dalam pemeriksaan tajam penglihatan menggunakan aplikasi perangkat lunak PEEK Acuity dengan jarak 2 meter antara responden dan layar telepon seluler (jarak pemeriksaan 1 meter bila ada instruksi dari aplikasi). Pemeriksaan tersebut juga sama di lakukan pada jurnal 4, pemeriksaan dengan menggunakan Tumbling E Snellen Chart di lakukan pada jarak 6 meter dan pada jarak 2 meter untuk aplikasi perangkat lunak PEEK Acuity. Namun adanya perbedaan pada jurnal 2, dalam pemeriksaan menggunakan Snellen Chart di lakukan pada jarak 3 meter dan untuk pemeriksaan aplikasi perangkat lunak PEEK Acuity dilakukan pada jarak 2 meter.

Berdasarkan dari hasil penelitian dari setiap jurnal menunjukkan bahwa aplikasi perangkat lunak PEEK Acuity tidak membutuhkan ruangan yang terlalu besar (6 meter). Dengan hal tersebut, aplikasi perangkat 
JURNAL SEHAT MASADA VOLUME XVI lunak PEEK Acuity bisa dilakukan dalam kegiatan bakti sosial atau rumah yang tidak terstandarisasi seperti di klinik yang memiliki ruang hingga 6 meter.

\section{4) Hasil tajam penglihatan}

Berdasarkan jurnal 1 ditemukan hasil pemeriksaan tajam penglihatan menggunakan PEEK Acuity sesuai dengan hasil pemeriksaan menggunakan Snellen Chart. Pada pemeriksaan mata kanan, 76 data $(92,68 \%)$ masuk dalam batas atas dan bawah limits of agreement $95 \% \quad(-0,19-0,37)$, sedangkan pemeriksaan pada mata kiri, 80 data $(97,56 \%)$ masuk dalam batas atas dan bawah limits of agreement $95 \%(-0,35-0,51)$. Distribusi data seluruh hasil pemeriksaan tajam penglihatan didapatkan tidak normal, sehingga digunakan uji non para-metrik Wilcoxon Signed Ranks Test untuk membandingkan hasil pemeriksaan tajam penglihatan monokuler Snellen Chart dan PEEK Acuity. Ditemukan perbedaan signifikan hasil pemeriksaan tajam penglihatan mata kanan menggunakan kartu Snellen (median $=0,10)$ dan PEEK Acuity ( median $=0,00) ; Z=-4,93 ; p=0,00$. Perbedaan signifikan juga didapatkan pada hasil pemeriksaan tajam penglihatan mata kiri menggunakan Snellen Chart $($ median $=0,17)$ dan PEEK Acuity (median=0,01); Z=-4,831; $\mathrm{p}=0,00$.

Sebanding dengan hasil penelitian yang dilakukan pada jurnal 2, Perbedaan rata-rata antara tes berbasis telepon pintar dan ETDRS dan tes berbasis telepon pintar dan data Snellen Acuity adalah 0,07 (95\% CI, 0,05-0,09) dan $0,08 \quad(95 \% \quad \mathrm{CI}, \quad 0,06-0,10) \quad \log M A R$,
NOMOR 1 Januari 2022 ISSN : 1979-2344 menunjukkan bahwa ketajaman tes berbasis telepon pintar cocok (sebanding) dengan grafik ETDRS dan Snellen Chart. Terbukti dengan perbedaan rata antara Snellen Chart di rumah dengan aplikasi perangkat lunak PEEK Acuity di rumah 0,029, Snellen Chart di klinik dengan aplikasi perangkat lunak di klinik -0,078 dengan menggunakan analisis korelasi BlandAltman Plot.

Berbeda dengan hasil penelitian pada jurnal 4, didapatkan sensitivitas 48\%, spesifisitas $83 \%$, $43 \%$ nilai prediktif positif, dan $86 \%$ nilai prediktif negative untuk kemampuan PEEK Acuity sebagai bahan rujukan, dibandingkan dengan evaluasi oleh dokter spesialis mata anak, PEEK Acuity gagal mencapai sensitivitas yang diinginkan untuk pengimplementasian. PEEK Acuity cenderung terus untuk melebih-lebihkan ketajaman visual pasien.

Sehingga dapat disimpulkan bahwa penggunaan aplikasi perangkat lunak PEEK Acuity dapat disarankan untuk melakukan screening awal karena sensifitasnya yang tinggi, sehingga dapat menekan kejadian kelainan refraksi yang tidak ter koreksi. Dan juga, tidak disarankan untuk di jadikan rujukan dan/atau digunakan untuk alat utama pemeriksaan visus secara komprehensif di klinik di karenakan hasil penelitian pada jurnal 4 yang menyatakan bahwa PEEK Acuity cenderung melebih-lebihkan hasil tajam penglihatan. Tentunya, pemeriksaan tajam penglihatan dapat dilatihkan kepada guru di sekolah-sekolah dasar guna memeriksakan kesehatan mata sedini mungkin 


\section{KESIMPULAN}

- Efisiensi waktu penggunaan PEEK Acuity lebih cepat dibanding dengan Snellen Chart.

- Aplikasi perangkat lunak PEEK Acuity tidak membutuhkan ruangan yang terlalu besar seperti Snellen Chart.

- Aplikasi perangkat lunak PEEK Acuity memang membutuhkan biaya yang lebih besar jika dibandingkan dengan Snellen Chart karena membutuhkan telepon seluler terutama dengan model dengan kualitas layar yang berkualitas tinggi.

- Penggunaan aplikasi perangkat lunak PEEK Acuity dapat disarankan untuk melakukan screening awal karena sensifitasnya yang tinggi. Namun, tidak disarankan untuk di jadikan rujukan dan/atau digunakan untuk alat utama pemeriksaan visus secara komprehensif di klinik.

\section{DAFTAR PUSTAKA}

Bastawrous A, R. H. L. I. W. H. J. S. K. H., 2015. Development and Validation of a Smartphone-Based Visual Acuity Test (Peek Acuity) for Clinical Practice and Community-Based Fieldwork. 8 ed. s.1.:JAMA Opthalmol.

Brady C, E. A. L. A., 2015. SmarthphoneBased visual acuity measurement for screening and clinical assessment. s.l.:JAMA Opthalmol.

Butterworth \& Heinemann, 2002. Glosarry of Opthometry. Jordan Hill Britania Raya: Reed Elsevier.

Chen F, A. L. P. K. T. J. W. E., 2014. Factors contributing to discrepacny between visual acuity fractions derived from a Snellen Chart and letter scores on the early treatment diabetic retinopathy
NOMOR 1 Januari 2022 ISSN : 1979-2344 study chart. 5 ed. s.l.:Asia-Pasific J Opthalmol.

Cicendo Eye Hospital, 2019. Pengukuran Tajam Penglihatan dgn Smartphone (PEEK Acuity). [Online]

Available at:

https://www.cicendoeyehospital.org/ind ex.php/component/content/article/642pengukuran-tajam-penglihatan-dgnsmartphone-peek-acuity.html [Accessed 20 January 2020].

Colenbrander, A., 2008. The Historical Evolution of Visual Acuity Measurement. Informa Healthcare, p. 63.

DuBois, L., 2006. Clincical Skills for the Opthalmic Examination Basic Procedures. 2nd ed. Atlanta, Georgia: Slack Incorporated.

Essilor Academy Europe, 2008. Practical Refraction. 1st ed. Paris: Essilor.

Hashemi, H. et al., 2017. Review Global and regional estimates of prevelance of refractive errors: Systematic review and meta-analysis.

Ilyas, S., 1995. Pemeriksaan Mata. Jakarta: Erlangga.

Ilyas, S. \& Yulianti, S. R., 2017. Ilmu Penyakit Mata. 4 ed. Jakarta: FKUI.

Inggito, A., 2016. Standar Prosedur

Pemeriksaan Refraksi untuk Refraksionis Optisien (Diploma Optometris). Jakarta: FKUI.

Masturoh, Imas; T., Nauri Anggita; 2018. Metodologi Penelitian Kesehatan; Bahan Ajar Rekam Medis dan Informasi Kesehetan (RMIK). 1st ed. s.l.:Pusat

Pendidikan Sumber Daya Manusia Kesehetan Badan Pengembangan dan Pemberdayaan Sumber Daya Manusia Kesehatan. 
JURNAL SEHAT MASADA VOLUME XVI

Notoatmodjo, S., 2018. Metodologi Penelitian Kesehatan. 3rd ed. Jakarta: PT Rineka Cipta.

Peraturan Menteri Kesehatan, 2015. Peraturan Menteri Kesehatan No. 41. s.1.:Menteri Kesehatan.

PK, K., 2009. A comparison of Snellen versus ETDRS charts in clinical practice, s.1.: Trans Am Opthalmol Soc..

Pusat Data dan Informasi Kementerian Kesehatan RI, 2014. Situasi Gangguan Penglihatan dan Kebutaan. p. 2.

Pusat Data dan Informasi Kementerian Kesehatan RI, 2018. InfoDATIN Situasi Gangguan Penglihatan. p. 4.

Putranto, K., 2017. Kesesuaian Hasil Pemeriksaan Tajam Penglihatan Jauh Menggunakan Aplikasi perangkat lunak Peek Acuity dan Kartu Baca ETDRS Pada Subjek dengan Gangguan Penglihatan Sedang-Berat, Bandung: Departemen Ilmu Kesehatan Mata Fakultas Kedokteran Universitas Padjajaran Pusat Mata Nasional Rumah Sakit Mata Cicendo Bandung.

Witjaksono, A. \& Riani, N., 2018. Perbandingan Penentuan Best Visus Sphere (BVS) dengan menggunakan metode fog un fog dan duochrome.

World Health Organization, 2013. Online $Q \& A$. [Online]

Available at: https://www.who.int/features/qa/45/en/ [Accessed 30 December 2019].

Evani, S. dkk., 2019. Perbandingan Hasil Pemeriksaan Tajam Penglihatan Menggunakan Snellen Chart dan Aplikasi telepon pintar PEEK Acuity pada Anak Usia 5-6 Tahun. vol. 46, no. 8, dilihat 7 April 2020 https://kalbemed.com/DesktopModules/ EasyDNNNews/DocumentDownload.as $\mathrm{hx}$ ?portalid=0\&moduleid $=471 \&$ articleid $=736 \&$ documentid $=712$
NOMOR 1 Januari 2022 ISSN : 1979-2344

Brady, J. Christoper. et al., 2015 SmartphoneBased Visual Acuity Measurement for Screening and Clinical Assessment. dilihat 7 April 2020.

https://www.ncbi.nlm.nih.gov/pmc/articl es/PMC4913699/

Venecia, de Bryce. et al., 2018. Validation of PEEK Acuity applications in pediatric screening programs in Paraguay. dilihat 7 April 2020.

https://www.ncbi.nlm.nih.gov/pmc/articl es/PMC6090125/

Statista, 2020. Smartphone user in Indonesia [Online]

https://www.statista.com/statistics/2667 29/smartphone-users-in-indonesia/ [dilihat 15 Juli 2020] 